\title{
Hematological Indices of Pesticide Exposure on Rice Farmers in Southern Thailand
}

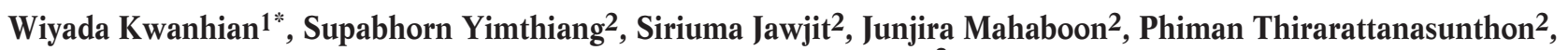 \\ Udomratana Vattanasit ${ }^{2}$
}

\author{
${ }^{1}$ School of Allied Health Sciences, Walailak University, Thailand, ${ }^{2}$ School of Public Health, Walailak University, \\ Thailand
}

\begin{abstract}
The most common pesticides used in rice farming are organophosphates and carbamates. These pesticides inhibit acetylcholinesterase (AChE) activity, resulting in excessive levels of acetylcholine accumulation and disrupted neurotransmission. This study compared AChE activity and hematological parameters between pesticide-using rice farmers, non-pesticide-using rice farmers, and non-agricultural occupational groups (non-farmers). Pesticide residues that accumulated in the rice, water, and soil of the study area were also determined. AChE activity of all participants showed 10 out of 87 samples (11.49\%) as borderline depressed, with $50 \%$ of those being pesticide-using farmers. Most of the hematological parameters were normal in all samples. However, platelet numbers of self-spraying pesticide rice farmers were significantly lower than those of non-self-spraying rice farmers. The results suggested that the use of pesticides during rice farming affected AChE activity and some hematological cells. Besides, pesticide residues in soil, water, and rice in the fields using pesticides were higher than in non-pesticide use areas. Results confirmed that the farmers using pesticides experienced higher exposure rates than farmers who did not use pesticides.
\end{abstract}

Keywords: Acetylcholinesterase, hematological indices, pesticide, rice farmer

\section{Introduction}

The main agricultural occupation in Asia is rice farming. For Thailand, approximately $40.9 \%$ of the total land area is used for agricultural production, with $31.3 \%$ and $27.8 \%$ as forest and unclassified land, respectively. Approximately, $49.8 \%$ of the agricultural land is used for growing rice; $21.5 \%$ for field crops, $21.2 \%$ for fruit or horticultural crops, and $7.5 \%$ for others. Thailand is nearly self-sufficient in terms of food production; agriculture is an important sector and is the largest source of employment for the rural population. Approximately, $46.6 \%$ of the total population is engaged in the agricultural sector. ${ }^{1}$

Chemicals are used in agriculture to promote high production yields, with several types used as pesticides. The major groups of synthetic organic pesticides are or-

How to Cite: Kwanhian W, Yimthiang S, Jawjit S, Mahaboon J, Thirarattanasunthon $P$, Vattanasit U. Hematological indices of pesticide exposure on rice farmers in Southern Thailand. Kesmas: National Public Health Journal. 2019; 14(1): 37-42. (doi: 10.21109/kesmas.v14i1.2812) ganophosphates, carbamates, and pyrethroids. Most of these are classified as class III, slightly hazardous, with over $2,000 \mathrm{mg} / \mathrm{kg}$ body weight Lethal Doses (LD50) for rats by both oral and dermal exposure. ${ }^{2}$ Although most pesticides are legally allowed chemicals, their use may be harmful to farmers, consumers, and the environment if they are not handled properly with appropriate precautionary methods.

The organophosphate and carbamate pesticides are neurotoxic via acetylcholinesterase (AChE) inhibition, with AChE unable to bind acetylcholine to terminate synaptic transmission. Inhibition of AChE in humans can cause many acute symptoms including dizziness, nausea, difficulty in breathing, and even death. In addition, a non-specific effect results in induced reactive oxygen species that attacks lipids, proteins, and deoxyribonucleic

Correspondence $^{*}$ : Wiyada Kwanhian, School of Allied Health Sciences, Walailak University, Nakhon Si Thammarat, Thailand 80160, Phone: +66-75672703, Fax: +66-75-672702, E-mail: wiyadakwanhian@gmail.com Received : December $15^{\text {th }} 2018$

Revised : May $10^{\text {th }} 2019$

Accepted : June $12^{\text {th }} 2019$ 
acid (DNA), causing oxidation and membrane damage, enzyme inactivation, DNA damage, and cell death. ${ }^{3}$ Several authors have investigated the adverse hematological effects of organophosphate on blood hemoglobin, hematocrit level, red blood cell numbers, platelet numbers, and white blood cell numbers. ${ }^{4,5}$

Because of these known adverse effects of pesticides, many studies have been done. Results suggest that Thai agricultural workers are exposed to pesticides. ${ }^{6-9}$ However, there not many studies have examined the effects of pesticide use on hematological indices in rice farmers, particularly in Southern Thailand. To provide farmers with a better quality of life, surveillance for poisoning caused by occupational pesticide exposure is necessary. Therefore, the major aim of this study was to investigate the red blood cell AChE and hematological status of rice farmers in Southern Thailand that employed pesticides during the planting process, compared to non-pesticide-using farmers and non-farmers as control groups.

\section{Method}

The selected areas of the present study were Pak Phanang Fang Tawan Tok, Pak Phanang, and Nakhon Si Thammarat, Thailand. The earlier studies reported that the pesticides used in this area were mainly organophosphates and carbamate. It is also reported that the top three pesticides for which residues were found to contaminate rice fields and rice grain were parathion methyl, fipronil, and chorpropham, respectively. ${ }^{10}$ Population sample size was calculated using the Yamane formula with 0.1 degrees of error from a population of 5,711 individuals. The total number of sample should not be less than 98 . In this study, there were 102 participants comprised of 37 pesticide-using rice farmers, 31 non-pesticide-using rice farmers, and 34 non-farmers (non-agricultural occupation). The samples were selected using a systematic sampling method. Inclusion criteria for pesticide-using rice farmers consisted of rice farmers aged between 18 and 60 years who used pesticides in their cultivation processes. For non-pesticide-using rice farmers, the inclusion criteria was rice farmers in the same 18-60-year age range who did not use pesticides in their cultivation processes. For the non-agricultural occupational samples, the inclusion criteria were defined as the same 18-60-year age range for people whose occupation was not involved with agriculture. Individuals with records of diseases, including various cancers and hematologic, respiratory, cardiovascular, gastrointestinal, and endocrine system illnesses, were excluded.

Certified nurses or medical technologists drew six milliliters of blood from veins in participants' arms and split it into two Ethylenediaminetetraacetic acid (EDTA) collecting tubes. Demographic data and information on pe- sticide use were collected by researchers and trained interviewers. There were 50 questions asked, which required approximately 30 minutes per interview. Most questions were either yes or no, dichotomous types or multiple choice, offering several fixed alternatives. In addition to inquiring about demographic characteristics, cultivation methods, and methods of mixing, application, and storage of pesticides, as well as toxicological side effects, the questionnaire inquired about the varieties of pesticides used, and the participants' knowledge about pesticides, attitude, and practices. The questionnaire and this study were reviewed and authorized by the Human Research Ethics Committee, Walailak University, Thailand (WU_010/2017).

AChE activity was determined by a modified electrometric method. ${ }^{11}$ In brief, $3 \mathrm{ml}$ of distilled water was placed in a $10 \mathrm{ml}$ beaker; then $3 \mathrm{ml}$ of barbital phosphate buffer was added, followed by $0.2 \mathrm{ml}$ of blood. The $\mathrm{pH}$ of the mixture was measured just after the substrate as 0.1 $\mathrm{ml}$ of $27.5 \mathrm{mM}$ acetylcholine iodide was added, and the mixture was then placed in a water bath at $37^{\circ} \mathrm{C}$ for 20 min before the $\mathrm{pH}$ was re-measured. The activity was calculated as the change in $\mathrm{pH}$ over the $20 \mathrm{~min}(\Delta \mathrm{pH} / 20$ min). If $\Delta \mathrm{pH}$ was higher than 1.15 , the $\mathrm{AChE}$ activity was normal. A $\Delta \mathrm{pH}$ value between $1.0-1.15$ indicated borderline depressed AChE activity, while $\Delta \mathrm{pH}$ lower than 1.0 indicated severely depressed AChE activity.

Blood was analyzed using an electrical impedance automatic cell counter (Beckman Coulter) for parameters including hemoglobin $(\mathrm{Hb})$, hematocrit $(\mathrm{Hct})$, white blood cell count (WBC), percentage of WBC differentiation (neutrophil, lymphocyte, monocyte, eosinophil, and basophil), and platelet count. The 24 soil and 19 water samples from rice fields were collected from the study area in Nakhon Si Thammarat Province. The soil was collected following the manual instructions for soil sampling and soil analysis methods. ${ }^{12}$ Water was collected following standard methods for the examination of water and wastewater. ${ }^{13}$ Unmilled rice was collected from four pesticide and eight non-pesticide-using rice fields.

A quantitative determination commercial, GTPesticide Residual test kit was used to determine pesticide contamination in the soil, water, and rice samples. The kit utilizes an AChE inhibition technique by observing the color changes. Organophosphate and/or carbamate are pesticides that interfere with the AChE enzyme activity. The detection limit is $0.05 \mathrm{mg} / \mathrm{kg}$ pesticide. ${ }^{14}$

One-way analysis of variance (ANOVA) was used to assess differences of the data for more than two sample groups (age of participants), and the independent t-test was used for two independent groups (red blood cell AChE activity and hematological parameters). Statistical analysis was performed using SPSS software Version 13.0 (IBM Corp., Armonk, NY, USA). 


\section{Results}

The 102 sample participants were divided into three groups which were 37 pesticide-using rice farmers, 31 non-pesticide-using rice farmers, and 34 non-farmers (other occupation). There were 49 males and 53 females with an average age of 53.5 years (Table 1). Only 87 blood samples were collected from the participants consisting of 34 pesticide-using rice farmers, 26 non-pesticide-using rice farmers, and 27 non-farmers. Most participants were older than 40 years, with no significant age differences among the three farming groups. Moreover, there was no evident relationship between participant age and AChE activity depression. Even though hematological parameters might be affected by age and sex, the present study results showed that the selected hematological parameters and sex parameters had no effect and were all normal.

AChE activity was not significantly different for sex, occupation, pesticide used in rice planting, self-pesticide spraying, and last time pesticide used in rice planting. The average AChE activity fell within a normal range (Table 2).

However, 10 samples $(11.49 \%)$ revealed borderline depressed AChE activity $(\triangle \mathrm{pH} 1.0-1.15)$, of which half (five samples) were pesticide-using farmers. The AChE activities of pesticide-exposed farmers were not critically depressed, but they were the largest group showing AChE activity depression (Table 3). The hematological effect of pesticides in this study was minor (Table 4). However, results indicated lower platelet numbers for self-spraying farmers who were directly exposed to pesticides than for those farmers who hired people to spray pesticides (Table 5).

Qualitative screening of samples from both non-pesticide and pesticide-using rice fields determined the pesticide residue that inhibited AChE activity (Table 6). Positive results from the screening assays indicated contamination of organophosphate and/or carbamate. The samples in this study were soil, water, and unmilled rice from each field. A total of 27 samples were collected from non-pesticide-using fields, and 28 samples were collected from pesticide-using rice fields. A total of 20 samples $(74.07 \%)$ from non-pesticide fields tested positive for pesticide screening; however, this was less than the pesticide-using fields, which revealed 25 samples $(89.29 \%)$ as positive. Five samples collected from pesticide-using fields tested positive at unsafe levels, whereas only three samples $(11.11 \%)$ from non-pesticide fields tested at unsafe levels.

Table 1. Demographic Data

\begin{tabular}{|c|c|c|c|c|c|c|}
\hline \multirow[t]{2}{*}{ Variable } & \multirow[t]{2}{*}{ Category } & \multirow[t]{2}{*}{ n $(\%)$} & \multicolumn{3}{|c|}{ Occupation } & \multirow[t]{2}{*}{ p-Value* } \\
\hline & & & $\begin{array}{l}\text { Pesticide-using } \\
\text { Rice Farmers }\end{array}$ & $\begin{array}{l}\text { Non-pesticide-using } \\
\text { Rice Farmers }\end{array}$ & $\begin{array}{l}\text { Non- } \\
\text { Farmers }\end{array}$ & \\
\hline \multirow[t]{2}{*}{ Sex } & Male & $49(48.00)$ & $22(59.46)$ & $16(51.62)$ & $12(35.29)$ & - \\
\hline & Female & $53(52.00)$ & $15(40.54)$ & $15(48.38)$ & $22(64.71)$ & - \\
\hline \multirow[t]{4}{*}{ Age (year) } & $<40$ & $24(23.50)$ & $8(21.62)$ & $8(25.81)$ & $8(23.53)$ & - \\
\hline & $40-50$ & $12(11.80)$ & $6(16.22)$ & $2(6.45)$ & $4(11.73)$ & - \\
\hline & $51-60$ & $44(43.10)$ & $17(45.94)$ & $15(48.38)$ & $12(35.29)$ & - \\
\hline & $>60$ & $22(21.60)$ & $6(16.22)$ & $6(19.36)$ & $10(29.45)$ & - \\
\hline Average age (year) & & 53.50 & 52.81 & 53.19 & 54.53 & 0.816 \\
\hline Total & & $102(100)$ & $37(36.27)$ & $31(30.39)$ & $34(33.34)$ & \\
\hline
\end{tabular}

Note: "Mean comparison of age between pesticide-using rice farmers, non-pesticide-using rice farmers, and non-farmers using ANOVA

Table 2. Red Blood Cell Acetylcholinesterase Activity

\begin{tabular}{|c|c|c|c|c|}
\hline Study Parameter & Category & $\mathbf{N}$ & $\begin{array}{l}\text { AChE activity* } \\
\Delta \mathrm{pH} \pm \mathrm{SD}\end{array}$ & p-Value $* *$ \\
\hline Total of Sample & $\mathrm{n}$ & 87 & $1.28 \pm 0.10$ & \\
\hline \multirow[t]{2}{*}{ Sex } & Male & 46 & $1.29 \pm 0.11$ & 0.411 \\
\hline & Female & 41 & $1.27 \pm 0.09$ & 0.411 \\
\hline \multirow[t]{2}{*}{ Occupation } & Farmer & 60 & $1.29 \pm 0.10$ & 0.915 \\
\hline & Non-farmer & 27 & $1.27 \pm 0.10$ & 0.915 \\
\hline \multirow{2}{*}{ Pesticide used in rice planting } & Yes & 34 & $1.28 \pm 0.11$ & 0.816 \\
\hline & No & 26 & $1.30 \pm 0.90$ & 0.816 \\
\hline \multirow{2}{*}{ Self-pesticide spraying } & No (hire) & 19 & $1.28 \pm 0.11$ & 0.267 \\
\hline & Yes & 15 & $1.29 \pm 0.12$ & 0.267 \\
\hline Last time that pesticide & $\leq 3$ months & 16 & $1.28 \pm 0.12$ & 0.940 \\
\hline was used in rice planting & $>3$ months & 17 & $1.29 \pm 0.11$ & 0.940 \\
\hline
\end{tabular}

Notes: *Normal AChE activity: $\Delta p H>1.15$, Borderline depressed AChE activity: $\Delta p H$ 1.0-1.15,

Severely depressed AChE activity: $\triangle p H<1.0$

**Independent $t$-tests 
Table 3. Acetylcholinesterase Activity of Sample Groups

\begin{tabular}{lrrc}
\hline Sample group & $\mathbf{n}(\%)$ & \multicolumn{2}{c}{ AChE activity* } \\
\cline { 3 - 4 } & & Normal n(\%) & Borderline depressed n(\%) \\
\hline Pesticide-using rice farmers & $34(39.08)$ & $29(85.29)$ & $5(14.71)$ \\
Non-pesticide-using rice farmers & $26(29.89)$ & $24(92.31)$ & $2(7.69)$ \\
Non-farmers & $27(31.03)$ & $24(88.89)$ & $3(11.11)$ \\
Total & $87(100.00)$ & $77(88.51)$ & $10(11.49)$ \\
\hline
\end{tabular}

Note: "Normal AChE activity: $\Delta p H>1.15$, Borderline depressed AChE activity: $\Delta p H$ 1.0-1.15, Severely depressed AChE activity: $\triangle p H<1.0$

Table 4. Hematological Parameters

\begin{tabular}{|c|c|c|c|c|c|}
\hline \multirow[t]{2}{*}{ Parameters } & \multirow[t]{2}{*}{ Normal range } & \multicolumn{3}{|c|}{ Mean \pm S.D. } & \multirow[t]{2}{*}{ p-Value* } \\
\hline & & $\begin{array}{c}\text { Total sample } \\
n=90\end{array}$ & $\begin{array}{c}\text { Farmers } \\
n=61\end{array}$ & $\begin{array}{c}\text { Non-farmers } \\
n=29\end{array}$ & \\
\hline $\mathrm{Hb}(\mathrm{gm} \%)$ & $12.0-16.4$ & $13.22 \pm 1.73$ & $13.38 \pm 1.64$ & $12.88 \pm 1.87$ & 0.194 \\
\hline Het $(\%)$ & $36.1-50.3$ & $40.78 \pm 5.09$ & $41.19 \pm 4.91$ & $39.91 \pm 5.44$ & 0.267 \\
\hline WBC count $\left(\mathrm{x} 10^{3}\right.$ cells $\left./ \mu \mathrm{l}\right)$ & $4.0-11.0$ & $6.86 \pm 3.46$ & $6.79 .25 \pm 1.99$ & $7.00 \pm 5.43$ & 0.778 \\
\hline \multicolumn{6}{|l|}{ WBC differentiation $(\%)$} \\
\hline Neutrophil & $54-62$ & $45.10 \pm 11.18$ & $46.26 \pm 10.29$ & $42.66 \pm 12.69$ & 0.154 \\
\hline Lymphocyte & $25-35$ & $42.49 \pm 9.19$ & $41.52 \pm 9.11$ & $44.52 \pm 9.17$ & 0.150 \\
\hline Monocyte & $3-7$ & $7.62 \pm 2.39$ & $7.75 \pm 2.69$ & $7.34 \pm 1.56$ & 0.367 \\
\hline Eosinophil & $1-3$ & $4.66 \pm 4.50$ & $4.31 \pm 3.64$ & $5.38 \pm 5.92$ & 0.295 \\
\hline Basophil & $0-5$ & $0.13 \pm 0.40$ & $0.15 \pm 0.44$ & $0.10 \pm 0.31$ & 0.630 \\
\hline Platelet $(103$ cells $/ \mu \mathrm{l})$ & $140-400$ & $274 \pm 79$ & $265 \pm 84$ & $291 \pm 68$ & 0.152 \\
\hline
\end{tabular}

Notes: "p-value calculated by independent t-test between farmer and non-farmer groups; Hb = Hemoglobin; Hc = Hematocrit; $W B C=$ White blood cells

\section{Discussion}

According to the participating farmers' demographic data, the majority of samples were males between 51 and 60 years old. This result was consistent with the general characteristics of a Thai farmer; that is, male and older. A documentary by the Food and Agriculture Organization (2000) stated that only the older generation continues to farm rice. It was also noted that the average age of the farmers in the study area was higher than the average age of those in Thailand (46.01 years old). ${ }^{15}$ This result is also consistent with socio-economic study of rice farmers, which found that most farmers were male. ${ }^{16-18}$

In this study, RBC AChE was selected for determination instead of serum cholinesterase (ChE). This is because AChE is the true cholinesterase that is present in the brain and erythrocyte, while ChE is pseudo cholinesterase that is present only in serum. Prior studies demonstrated that AChE activity was suppressed by every organophosphate used in the experiment, including fenthion, chlorpyrifos, diazinon, bromophos, propaphos, haloxon, and DFP, while only a few organophosphates can be suppressed in serum isoenzyme ChE. ${ }^{19}$

The average AChE of all samples was normal. However, approximately $11.49 \%$ (10 samples) had borderline depressed AChE activity. Among this group, half were pesticide-using farmers. These results indicate that pesticide-using farmers were at high-risk of AChE inhibi- tor exposure, confirming several previous results. ${ }^{20-23}$ The other five depressed AChE activity samples consisted of two non-pesticide-using rice farmers and three nonfarmers. This result indicates that they might have been exposed to pesticides, especially AChE inhibitors that contaminated food, water, and the environment, possibly from home pesticide products. ${ }^{24,25}$

As seen in Table 4, the blood indices for farmers and non-farmers were not significantly different. However, if analyzing the difference self-pesticide spraying and nonself-spraying farmers, the results showed a difference in platelet count that was lower in the self-spraying group. These findings indicated that self-spraying pesticide farmers had a higher chance of exposure to pesticides, which adversely affected their platelet numbers. Previous reports showed that pesticide exposure resulted in hematological changes not only in platelets but also white and red blood cells. ${ }^{25} \mathrm{AChE}$ is found in neuron synapses and red blood cells, as well as in platelets and megakaryocyte cells. ${ }^{25}$ Hence, the inhibition of AChE might affect platelet numbers. However, because the participant ages averaged 53.50 years, it is possible that old age might be the influencing factor for the effect seen in the hematological indices. ${ }^{26,27}$

In this study, pesticide and non-pesticide-using farmer groups did not show significantly affected hemoglobin and hematocrit levels compared to the control and nor- 
Table 5. Hematological Parameters of Rice Farmers Using Pesticides

\begin{tabular}{lccc}
\hline & \multicolumn{2}{c}{ Mean \pm S.D. } \\
\cline { 2 - 3 } Parameter & $\begin{array}{c}\text { Self-pesticide Spraying } \\
\mathbf{n}=\mathbf{1 6}\end{array}$ & $\begin{array}{c}\text { Non-self-pesticide Spraying } \\
\mathbf{n}=\mathbf{1 6}\end{array}$ & p-Value* \\
\hline Hb (gm\%) & $13.59 \pm 1.24$ & $13.38 \pm 1.06$ & 0.588 \\
Hct $(\%)$ & $41.79 \pm 3.43$ & $40.96 \pm 3.81$ & 0.513 \\
WBC count $(103$ cells/ $\mu 1)$ & $6.92 \pm 2.32$ & $6.83 \pm 2.89$ & 0.910 \\
Neutrophil & $45.31 \pm 9.50$ & $46.67 \pm 11.31$ & 0.710 \\
Lymphocyte & $42.25 \pm 8.68$ & $39.89 \pm 8.04$ & 0.416 \\
Monocyte & $8.44 \pm 3.29$ & $7.56 \pm 3.15$ & 0.430 \\
Eosinophil & $4.00 \pm 2.13$ & $5.61 \pm 5.40$ & 0.255 \\
Basophil & $0.00 \pm 0.00$ & $0.28 \pm 0.57$ & 0.056 \\
Platelet $(103$ cells $/ \mu 1)$ & $214 \pm 67$ & $283 \pm 77$ & $0.010^{* * *}$ \\
& & & \\
\hline
\end{tabular}

Notes: "p-value calculated by independent t-test, ${ }^{* * *}$ : significant different ( $p$-value $<0.05$ );

$H b=$ Hemoglobin $; \mathrm{Hc}=$ Hematocrit $; W B C=$ White blood cells

Table 6. Qualitative Pesticide Residue Contamination in Rice Samples and the Environment

\begin{tabular}{|c|c|c|c|c|c|c|c|c|}
\hline \multirow{4}{*}{ Sample type } & \multirow[b]{4}{*}{ No. } & \multicolumn{7}{|c|}{ Pesticide Residue Contamination a } \\
\hline & & \multicolumn{3}{|c|}{ Samples of Non-pesticide Fields (\%) } & \multicolumn{4}{|c|}{ Samples of Pesticide Fields (\%) } \\
\hline & & \multirow[t]{2}{*}{ Negative $b$} & \multicolumn{2}{|c|}{ Positive } & \multirow[b]{2}{*}{ No. } & \multirow[t]{2}{*}{ Negative $b$} & \multicolumn{2}{|c|}{ Positive } \\
\hline & & & Safety Level c & Unsafety Level d & & & Safety Level c & Unsafety Level d \\
\hline Soil & 11 & $4(36.36)$ & $4(36.36)$ & $3(27.28)$ & 13 & $1(7.69)$ & $8(61.53)$ & $4(30.78)$ \\
\hline Water & 8 & - & $8(100.00)$ & - & 11 & $1(9.09)$ & $9(81.82)$ & $1(9.09)$ \\
\hline Unmilled rice & 8 & $3(37.50)$ & $5(62.50)$ & - & 4 & $1(25.00)$ & $3(75.00)$ & - \\
\hline Total & 27 & $7(25.93)$ & $17(62.96)$ & $3(11.11)$ & 28 & $3(10.71)$ & $20(71.43)$ & $5(17.86)$ \\
\hline
\end{tabular}

Notes: a Pesticide residue determined by GT-Pesticide Residual test kit, b Negative: pesticide level lower than $0.05 \mathrm{mg} / \mathrm{kg}$ (detection

limit), c Positive with safe level: pesticide detected but within safety level, d Positive at unsafe level: pesticide detected at an unsafe level

mal range levels. However, surveillance and caution must be maintained in the use of pesticides. Contaminated environmental and rice samples from pesticide-using fields screened positive at a higher rate than non-pesticide using fields. Results confirm that farmers in pesticide using fields had higher organophosphate and/or carbamate exposure risk from pesticide self-spraying and rice consumption. The $74.04 \%$ positive samples from nonpesticide fields might have been contaminated from nearby fields. Therefore, non-pesticide-using rice fields in our study were non-true pesticide residue-free areas. Findings indicate that pesticide-free planting still experienced management problems within the study area.

\section{Conclusion}

Half $(50 \%)$ of AChE borderline depressed activity sample participants are pesticide-using farmers, while the others are both pesticide-using farmers and non-farmers. Most hematological parameters are normal in all samples. However, platelet numbers of pesticide self-spraying rice farmers are significantly lower than non-self-spraying rice farmers. The results suggest that the use of pesticides in rice farming affects AChE activity and some hematological indices. Besides, pesticide residue environment samples, and rice from pesticide fields show higher pesticide contamination rates than in non-pesticide areas. These results indicate and confirm that the farmers in pesticide-using areas are at a higher risk of pesticide exposure than non-pesticide-using farmers.

However, this study was conducted in only one subdistrict of Nakhon Si Thammarat Province. Therefore, further study is recommended in a wider area that covers all provinces of Southern Thailand. Moreover, the further study might include additional agricultural farmer types other than just rice farmers, such as oil palm planters and rubber planters; these are both famous occupations in Southern Thailand and may also be interesting to study.

\section{Acknowledgment}

This study was supported by a grant from the Areabased Collaborative Research Project between the Thailand Research Fund and Walailak University. The contributions of each author are as follows: WK was the main operator and corresponding author. SY was the chief operator and co-author. SJ, PT, JM, and UV were the co-authors.

\section{References}

1. Thepent V, editor. Agricultural mechanization in Thailand The 16 th TSAE National Conference and 8th TSAE International Conference; 2015 March 17-19; Bangkok, Thailand.

2. World Health Organization. The WHO recommended classification of pesticides by hazard and guidelines to classification: 2009 . Wissenchaftliche Verlagsgesellschaft mbH, Stuttgart, Germany; 2010. 
3. Colovic MB, Krstic DZ, Lazarevic-Pasti TD, Bondzic AM, Vasic VM. Acetylcholinesterase inhibitors: pharmacology and toxicology. Current Neuropharmacology. 2013; 11(3): 315-35.

4. Araoud M, Neffeti F, Douki W, Hfaiedh HB, Akrout M, Hassine M, et al. Adverse effects of pesticides on biochemical and haematological parameters in Tunisian agricultural workers. Journal of Exposure Science and Environmental Epidemiology. 2012; 22(3): 243-7.

5. Hu R, Huang X, Huang J, Li Y, Zhang C, Yin Y, et al. Long- and shortterm health effects of pesticide exposure: A cohort study from China. PLoS One. 2015; 10(6): e0128766.

6. Tawatsin A. Pesticides used in Thailand and toxic effects to human health. Medical Research Archives. 2015; 1(3): 1-10.

7. Panuwet P, Siriwong W, Prapamontol T, Ryan PB, Fiedler N, Robson MG, et al. Agricultural pesticide management in Thailand: Situation and population health risk. Environmental Science \& Policy. 2012; 17: 72 81.

8. Tongpoo A, Sriapha C, Wongvisawakorn S, Rittilert P, Trakulsrichai S, Wananukul W. Occupational carbamate poisoning in Thailand. The Southeast Asian Journal of Tropical Medicine and Public Health. 2015; 46(4): 798-804.

9. Wongta A, Sawarng N, Tongchai P, Sutan K, Kerdnoi T, Prapamontol $\mathrm{T}$, et al. The pesticide exposure of people living in agricultural community, Northern Thailand. Journal of Toxicology. 2018; 2018: Article ID 4168034.

10. Jawjit S, Kwanhian W, Vattanasit U, Thirarattanasunthon P, Yimthiang S, Mahaboon J, et al. A Comparison of knowledge, attitudes, and practices of rice farmers and levels of pesticide residues in the environment in Nakhon si Thammarat Province. Journal of Safety and Health. 2017; 10(37): 10-20

11. Abdullah KK, Sakran AK. The measurements of the cholinesterase activity of brain and plasma in rabbits by using modified Michel and Ellman assays. Insights in Enzyme Research. 2017; 1.

12. Estefan G, Sommer R, Ryan J. Methods of soil and plant, and water analysis: A manual for the West Asia and North Africa region. 3rd, editor: Jointly published by the International Center for Agricultural Research in the Dry Areas (ICARDA); 2014.

13. Rice EW, Bridgewater L. Standard methods for the examination of water and wastewater: American Public Health Association, American Water Works Association, Water Environment Federation; 2012.

14. GT Pesticide test kit [homepage on the Internet]. Bangkok: GT trading; 2004 [updated 2018; cited 2019 Apr 15]; Available from: http://www.gttestkit.com/gttestkit_eng/contact_address.htm.

15. Kumpa L. Guideline for policies and agricultural development (power point presentation). Office of The National Economic and Social
Development Board, Thailand; 2015.

16. Ayoola J, Dangbegnon C, Daudu C, Mando A, Kudi T, Amapu I, et al. Socio-economic factors influencing rice production among male and female farmers in Northern Guinea Savanna Nigeria: Lessons for promoting gender equity in action research. Agriculture and Biology Journal of North America. 2011; 2(6): 1010-4.

17. Kennvidy S. Organic rice farming systems in Cambodia: Socio-economic impact of smallholder systems in Takeo Province. International Journal of Environmental and Rural Development. 2012; 2(1): 115-9.

18. Fakkhong S, Suwanmaneepong S. Socio-economic factors influencing rice production in peri-urban area, Bangkok, Thailand. International Journal of Agricultural Technology. 2015; 11(8): 2053-62.

19. Bajgar J. Laboratory examination in nerve agent intoxication. Acta Medica (Hradec Kralove). 2013; 56(3): 89-96.

20. Hayden KM, Norton MC, Darcey D, Ostbye T, Zandi PP, Breitner JC, et al. Occupational exposure to pesticides increases the risk of incident AD: The Cache County study. Neurology. 2010; 74(19): 1524-30.

21. Ntow WJ, Tagoe LM, Drechsel P, Kelderman P, Nyarko E, Gijzen HJ. Occupational exposure to pesticides: Blood cholinesterase activity in a farming community in Ghana. Archives of Environmental Contamination and Toxicology. 2009; 56(3): 623-30.

22. Thetkathuek A, Yenjai P, Jaidee W, Jaidee P, Sriprapat P. Pesticide exposure and cholinesteraselevels in migrant farm workers in Thailand. Journal of Agromedicine. 2017; 22(2): 118-30.

23. Varma A, Neupane D, Ellekilde Bonde J, Jørs E. Is prevention of acute pesticide poisoning effective and efficient, with locally adapted personal protective equipment? A randomized crossover study among farmers in Chitwan, Nepal. La Medicina del Lavoro. 2016; 107(4): 271-83.

24. Aktar M, Sengupta D, Chowdhury A. Impact of pesticides use in agriculture: Their benefits and hazards. Interdisciplinary Toxicology. 2009; 2(1): 1-12.

25. Fareed M, Pathak MK, Bihari V, Kamal R, Srivastava AK, Kesavachandran CN. Adverse respiratory health and hematological alterations among agricultural workers occupationally exposed to organophosphate pesticides: A cross-sectional study in North India. PLoS One. 2013; 8(7): e69755.

26. Mandala WL, Gondwe EN, MacLennan JM, Molyneux ME, MacLennan CA. Age- and sex-related changes in hematological parameters in healthy Malawians. Journal of Blood Medicine. 2017; 8: 123-30.

27. Chrysant SG, Chrysant GS. Age-Related Hemodynamic Changes of Blood Pressure and Their Impact on the Incidence of Cardiovascular Disease and Stroke: New Evidence. Journal of Clinical Hypertension. 2014; 16: 87- 9 . 